\title{
The distribution and source apportionment of aliphatic hydrocarbons in soils from the outskirts of Beijing
}

\author{
Youfeng Zhu a , Hui Liu ${ }^{a}$, Hangxing Cheng ${ }^{b}$, Zhiqun Xi ${ }^{\text {a }}$, \\ Xiufeng Liu ${ }^{\text {a }}$, Xiaobai $\mathrm{Xu}^{\text {a,* }}$ \\ ${ }^{a}$ Research Center for Eco-Environmental Sciences, Chinese Academy of Sciences, P.O. Box 2871, Beijing 100085, China \\ ${ }^{\mathrm{b}}$ Institute of Geochemical and Geophysical Exploration, Beijing 065000, China
}

Received 16 April 2004; accepted 7 September 2004

(returned to author for revision 15 August 2004)

Available online 9 December 2004

\begin{abstract}
We report the first extensive study of the spatial distribution and source apportionment of aliphatic hydrocarbons in soils from the Beijing outskirts. Mixed soil samples (5-30 cm depth) were collected for the quantitative determination of $n$-alkanes, isoprenoids, unresolved complex mixtures and the qualitative determination of hopanes and steranes. The total concentrations, including $n$-alkanes from $\mathrm{C}_{13}$ to $\mathrm{C}_{36}$, pristane and phytane, were in the range of $0.60-39.92 \mu \mathrm{g} /$ $\mathrm{g}$, with a median value of $1.97 \mu \mathrm{g} / \mathrm{g}$. No correlation between soil organic matter content or the percentage of clay and the concentrations was found. Carbon preference index (CPI) values for the whole range of $n$-alkanes varied between 0.73 and 4.27 , with a median value of 1.64 , and a contour map of CPI was drawn. A predominance of odd/even carbon $n$-alkanes and unresolved complex mixtures with different shapes and range were frequently observed. Factor analysis reduced the data set to two principal components explaining $82.82 \%$ of the total variation among samples and confirming contributions from low molecular weight species (63.66\%) and long-chain $n$-alkanes (19.27\%), respectively. Based on the principal component analysis, the concentration profiles and molecular markers, it was concluded that the aliphatic hydrocarbons were from both biogenic and anthropogenic sources.
\end{abstract}

(c) 2004 Published by Elsevier Ltd.

\section{Introduction}

In the past decades, aliphatic hydrocarbons and other lipid compounds in atmospheric aerosols and sediments in coastal oceanic environments have been studied to ascertain their terrestrial, marine or anthropogenic origins (Gagosian et al., 1981; Marty

\footnotetext{
${ }^{*}$ Corresponding author. Tel.: +86 10 82521355; fax: +86 10 62919177.

E-mail address: xuxb@public.bta.net.cn (X. Xu).
}

and Saliot, 1982; Prahl et al., 1984; Tolosa et al., 1996; Maldonado et al., 1999). Aliphatic hydrocarbons in urban aerosols were also widely studied (Aceves and Grimalt, 1993; Leuenberger et al., 1988) because of increasing consumption of fossil fuel. However, most attention was paid to carcinogenic polycyclic aromatic hydrocarbons. Until now, there are only limited reports on aliphatic hydrocarbons in soils. Nowadays, with petroleum exploration and the manufacturing of petroleum products, oil contamination in the environment is of worldwide concern. When leakage of oil to soil occurs, oil fractions will consequently pollute the air and 
groundwater through volatilization, partitioning and leaching. Aliphatic hydrocarbon analysis can be used to fingerprint spilled oils and to provide additional information on the source of hydrocarbon contamination and the extent of degradation of the spilled oil.

The origins of aliphatic hydrocarbons were often identified by diagnostic concentration indices together with molecular markers and multivariate methods (Kavouras et al., 2001; Colombo et al., 1989). Some indices that have been used for many years to identify biogenic and petrogenic sources are: (a) the major hydrocarbons (MHs); (b) low/high molecular weight hydrocarbons $(\mathrm{L} / \mathrm{H})$; (c) sum of total $n$-alkanes $/ n-\mathrm{C}_{16}$; (d) carbon preference index (CPI); (e) $n-\mathrm{C}_{17} /$ pristane $\left(\mathrm{C}_{17} / \mathrm{Pr}\right)$ and $n-\mathrm{C}_{18} /$ phytane $\left(\mathrm{C}_{18} / \mathrm{Ph}\right)$; and (f) unresolved complex mixtures (UCMs). Generally speaking, $n$-alkanes from vascular plant origins exhibit a predominance of odd/even carbon markers, higher CPI value and $\mathrm{MH}$ usually around $\mathrm{C}_{27}, \mathrm{C}_{29}, \mathrm{C}_{31}$, compared to those from petroleum related sources (Simoneit et al., 1991). Furthermore, aliphatic fractions extracted from carbon black, diesel soot, urban dust, chimney soot, wood charcoal and vegetation fire residues also show different characteristic diagnostic indices (Fernandes and Brook, 2003).

This paper presents the first extensive study of aliphatic hydrocarbons in soils from Beijing, the capital of China, which has developed at an explosive rate in the past two decades. Detailed information is given on the origins, concentrations and distributions of aliphatic hydrocarbons.

\section{Experimental}

\subsection{Sampling}

The sampling area was $816 \mathrm{~km}^{2}: 5 \mathrm{~km}$ east, $14 \mathrm{~km}$ south, $7 \mathrm{~km}$ west, and $6 \mathrm{~km}$ north from Beijing's fourth-ring road. Soil samples (5-30 cm depth) were collected every $1 \mathrm{~km}$, and 16 cores were pooled to obtain one representative sample for every $16 \mathrm{~km}^{2}$ area. Together, 47 samples were analyzed. The soil survey and sampling site map for the Beijing outskirts is shown in Fig. 1. The soil samples are brown and mostly sandy loam and silt loam. Each fully mixed sample was air dried under a hood at room temperature and sieved to pass a 35 mesh sieve. All samples were refrigerated at $-4^{\circ} \mathrm{C}$ until analysis.

\subsection{Materials}

All solvents, obtained from the Beijing Chemical Factory, were of analytical grade and were redistilled in an all-glass system before use. The $n$-alkane standards were purchased from ChemService Inc.

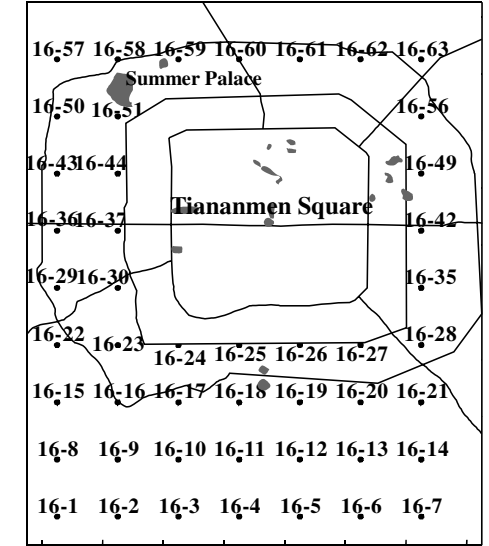
A. The third-ring road;
E. Beijing airport express;
B. The fourth-ring road;
F. Jingjingtang highway;
C. The fifth-ring road;
G. Jingshi highway.
D. The Badaling highway;

Fig. 1. Map of soil survey and sampling sites in the Beijing outskirts.

Silica gel (100-200 mesh; Qingdao Haiyang Chemical Co., Shangdong, China) was activated for $16 \mathrm{~h}$ at $130^{\circ} \mathrm{C}$ and kept in a desiccator until use. An aliquot (5 g) of each soil sample was weighed accurately and ground with $5 \mathrm{~g}$ anhydrous sodium sulfate. The sample was extracted with petroleum ether/acetone, 1/1 (v/v), using ultrasonication for $3 \mathrm{~min}$ and then centrifuged. This procedure was repeated three times. The extracts were combined and concentrated in volume to about $1 \mathrm{~mL}$.

For isolation of the alkane fraction, $10 \mathrm{~g}$ of activated silica gel was packed into a glass column using methylene chloride, covered with $2 \mathrm{~g}$ of anhydrous $\mathrm{Na}_{2} \mathrm{SO}_{4}$ at the top and then pre-washed using $40 \mathrm{~mL}$ petroleum ether. The sample was loaded on to the column and eluted with $25 \mathrm{~mL}$ of petroleum ether to obtain the alkane fraction. The fraction was concentrated to 0.2 $\mathrm{mL}$ under a gentle stream of nitrogen.

Quantitative analysis of the alkanes was carried out using an Agilent 6890 gas chromatograph equipped with FID and a DB- 5 column $(25 \mathrm{~m} \times 0.25 \mathrm{~mm}$ i.d., $0.25 \mu \mathrm{m}$ film thickness) with ultrapure nitrogen as carrier gas and make-up gas. Gas chromatography (GC) conditions were: injector and detector temperature 280 and 300 ${ }^{\circ} \mathrm{C}$, respectively, initial oven temperature $50^{\circ} \mathrm{C}$ held for 2 min then ramped to $280^{\circ} \mathrm{C}$ at $4{ }^{\circ} \mathrm{C} / \mathrm{min}$ and held for $10 \mathrm{~min}$. A $1 \mu \mathrm{L}$ sample was injected in the splitless mode and the purge valve was opened at $1 \mathrm{~min}$. Compounds were identified by retention time matched to external standards and were quantified using peak area integration.

Some samples were also analyzed using a HewlettParkard 6890 gas chromatograph coupled to a 5973 
MSD to confirm the identity of each compound. A DB-5 capillary column $(25 \mathrm{~m} \times 0.25 \mathrm{~mm}$ i.d., $0.25 \mu \mathrm{m}$ film thickness) was used. The GC oven programme was as described above. The scan range was $50-500 \mathrm{amu}$ and the ionization energy was $70 \mathrm{eV}$. The injector and transfer line temperature were 280 and $180^{\circ} \mathrm{C}$, respectively. Helium was the carrier gas. Data acquisition and processing were controlled using a HP Chem-Station data system.

For quality assurance and quality control, the method blanks (solvent) and spiked matrixes (standards spiked into soil) were analyzed. None of the target compounds was detected. The recovery and relative standard deviation for $\mathrm{C}_{13}-\mathrm{C}_{18}$ were in the range of $70.8-86 \%$ and $4.2-$ $19.3 \%$, respectively, and those for $\mathrm{C}_{19}-\mathrm{C}_{36}$ were in the range of $88.5-97.4 \%$ and $2.8-12.4 \%$, respectively. The detection limits of the method range from 3.1 and 12.4 $\mathrm{ng} / \mathrm{g}$. All concentrations were expressed on a soil dry weight basis.

Statistical analysis was performed with SPSS 12.0 for Windows Release 12.0.0 (4 Sep. 2003, SPSS Inc., 19892003).

\section{Results}

The concentrations (including $n$-alkanes from $\mathrm{C}_{13}$ to $\mathrm{C}_{36}$, Pr and $\mathrm{Ph}$ ), diagnostic indices of aliphatic hydrocarbons and soil properties are presented in Table 1 . The concentrations of 26 determined compounds were in the range $0.60-39.92 \mu \mathrm{g} / \mathrm{g}$ (median value $1.97 \mu \mathrm{g} / \mathrm{g}$ ). No correlations between the concentrations and soil organic matter content or the percentage of clay were found. The spatial distribution of the total concentra-

Table 1

Concentrations and compositional indices of aliphatic hydrocarbons in soil samples

\begin{tabular}{lccc}
\hline & Minimum & Maximum & Median \\
\hline SOM $(\mathrm{g} / \mathrm{kg})$ & 6.60 & 32.51 & 16.50 \\
Clay $(\%)$ & 6.80 & 22.33 & 11.02 \\
$\mathrm{SUM}(\mu \mathrm{g} / \mathrm{g})^{\mathrm{a}}$ & 0.60 & 39.92 & 1.97 \\
$\mathrm{C}_{n} / \mathrm{C}_{16}$ & 10.3 & 147.6 & 27.7 \\
$\mathrm{U} / \mathrm{R}$ & 0.29 & 10.44 & 2.08 \\
$\mathrm{C}_{17} / \mathrm{Pr}$ & 0.19 & 2.04 & 1.62 \\
$\mathrm{C}_{18} / \mathrm{Ph}$ & 0.60 & 1.98 & 1.47 \\
$\mathrm{Pr} / \mathrm{Ph}$ & 0.68 & 7.63 & 0.97 \\
$\mathrm{CPI}_{1}$ & 0.73 & 4.27 & 1.64 \\
$\mathrm{CPI}_{2}$ & 0.38 & 1.39 & 1.05 \\
$\mathrm{CPI}_{3}$ & 0.59 & 21.8 & 2.69 \\
$\mathrm{WaxC}_{n}(\%)$ & 10.52 & 59.02 & 26.58 \\
$\mathrm{~L} / \mathrm{H}_{1}{ }^{\mathrm{b}}$ & 0.05 & 1.66 & 0.49 \\
$\mathrm{~L}^{\mathrm{H}} \mathrm{H}_{2}{ }^{\mathrm{c}}$ & 0.08 & 6.42 & 0.84 \\
\hline
\end{tabular}

${ }^{a}$ Total amount of determined aliphatic hydrocarbons.

${ }^{b} \mathrm{~L} / \mathrm{H}_{1}$ : the ratios of low $\left(\mathrm{C}_{10}-\mathrm{C}_{24}\right)$ to high $\left(\mathrm{C}_{20}-\mathrm{C}_{36}\right)$.

c $\mathrm{L} / \mathrm{H}_{2}$ : low $\left(\mathrm{C}_{13}-\mathrm{C}_{24}\right)$ to high $\left(\mathrm{C}_{25}-\mathrm{C}_{36}\right) \mathrm{MW} n$-alkanes, respectively. tions of aliphatic hydrocarbons (Fig. 2) showed that relatively higher levels were clustered in the northeast and north sites of the city.

A data set containing 47 samples and 26 compounds (Table 2) was used for the principal component analysis.

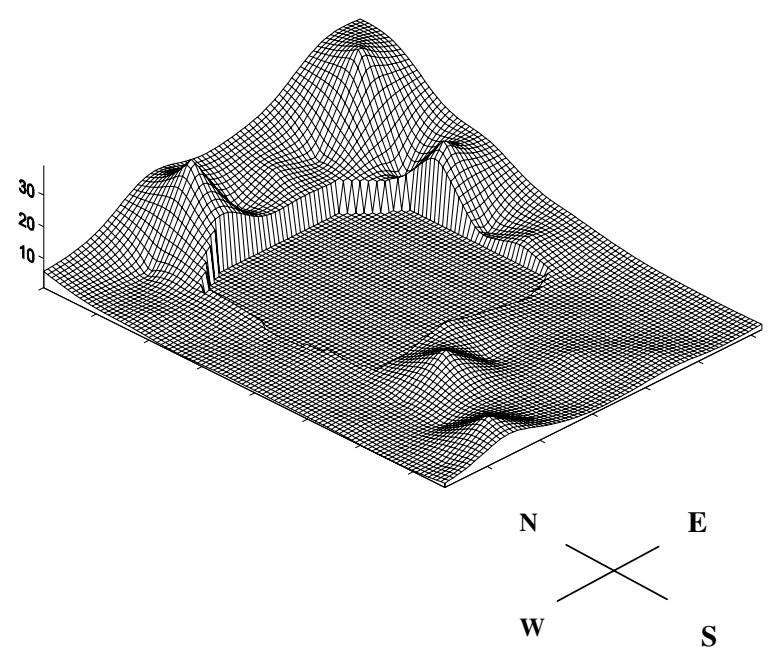

Fig. 2. The spatial distribution of aliphatic hydrocarbons in soils from the Beijing outskirts.

Table 2

Compounds analyzed $(\mu \mathrm{g} / \mathrm{g})$

\begin{tabular}{lllll}
\hline Compounds & Minimum & Maximum & Mean & SD $(n=47)$ \\
\hline$n-C_{13}$ & nd & 0.11 & 0.03 & 0.03 \\
$n-C_{14}$ & nd & 0.19 & 0.05 & 0.05 \\
$n-C_{15}$ & nd & 0.38 & 0.11 & 0.09 \\
$n-C_{16}$ & nd & 0.87 & 0.15 & 0.16 \\
$n-C_{17}$ & 0.03 & 1.58 & 0.22 & 0.28 \\
$\mathrm{Pr}$ & 0.02 & 0.87 & 0.15 & 0.17 \\
$n-C_{18}$ & 0.03 & 1.17 & 0.21 & 0.24 \\
$\mathrm{Ph}$ & 0.02 & 0.86 & 0.15 & 0.18 \\
$n-C_{19}$ & 0.01 & 0.87 & 0.16 & 0.17 \\
$n-C_{20}$ & 0.02 & 0.63 & 0.14 & 0.14 \\
$n-C_{21}$ & 0.02 & 0.68 & 0.12 & 0.14 \\
$n-C_{22}$ & 0.01 & 0.47 & 0.10 & 0.11 \\
$n-C_{23}$ & 0.02 & 0.58 & 0.10 & 0.12 \\
$n-C_{24}$ & 0.01 & 0.49 & 0.09 & 0.10 \\
$n-C_{25}$ & 0.02 & 2.04 & 0.26 & 0.45 \\
$n-C_{26}$ & 0.01 & 2.05 & 0.18 & 0.36 \\
$n-C_{27}$ & 0.01 & 3.36 & 0.42 & 0.64 \\
$n-C_{28}$ & nd & 3.70 & 0.27 & 0.61 \\
$n-C_{29}$ & 0.01 & 6.23 & 0.70 & 1.20 \\
$n-C_{30}$ & nd & 4.23 & 0.31 & 0.76 \\
$n-C_{31}$ & nd & 5.46 & 0.50 & 1.10 \\
$n-C_{32}$ & nd & 3.36 & 0.23 & 0.65 \\
$n-C_{33}$ & nd & 3.26 & 0.24 & 0.64 \\
$n-C_{34}$ & nd & 1.44 & 0.10 & 0.29 \\
$n-C_{35}$ & nd & 1.04 & 0.08 & 0.22 \\
$n-C_{36}$ & nd & 0.78 & 0.06 & 0.15
\end{tabular}

nd, not detected. In data processing, " $0.0002 \mu \mathrm{g} / \mathrm{g}$ ” was used to replace "nd". 
The first two principal components (PCs) account for $82.82 \%$ of the total variance, with eigenvalues $>1$. The combination of variables and their loadings is shown in Fig. 3(a). PC1 and PC2 were associated with low $\left(\mathrm{C}_{n}<24\right)$ and high $\left(\mathrm{C}_{n}>25\right)$ molecular weight $n$-alkanes and contained $63.55 \%$ and $19.27 \%$ of the total variance, respectively. By plotting the scores of the first two PCs, the sampling sites can be grouped in three clusters (Fig. 3(b)): (1) a first cluster with a single sample located in northeast of the city and which contained the highest amount of PC2, (2) a second cluster formed by the sample located in the north sites and characterized by the highest values of $\mathrm{PC} 1$, and (3) a dense third cluster containing the remaining samples that have the lowest values for both PCs.

\section{Discussion}

\subsection{Diagnostic indices}

UCMs are mainly composed of branched alkanes, cycloalkanes and aromatics and are one of the indicators of petrogenic inputs (Frysinger et al., 2003). One or two raised baseline humps can be observed in the gas chromatograms. The peaks usually appear near the $n-\mathrm{C}_{17}$ and $n$ - $\mathrm{C}_{27}$ alkanes, respectively (Doskey and Andren, 1986). In the present study, UCMs with different shapes and range were observed in most samples, suggesting a petroleum input to the soils in the Beijing area. The presence of a major UCM derived from petroleum residues was further confirmed by the presence of molecular
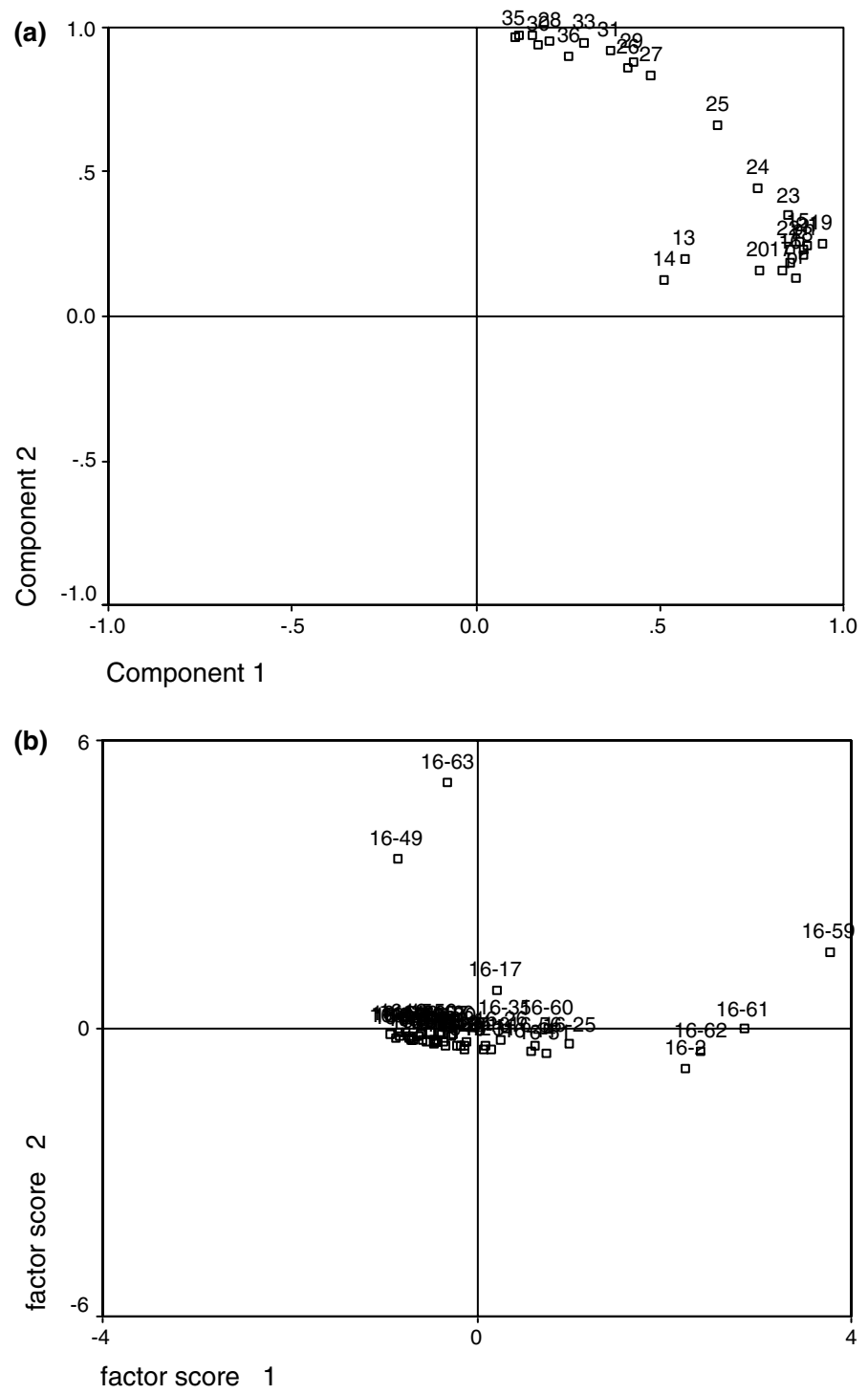

Fig. 3. (a) Loading and (b) score plots of the principal component analysis. 
markers as described below. In addition, bacteria may also be a source for small amount of UCM (Simoneit et al., 1991). The degree of petroleum contamination can be expressed as the ratio of the unresolved to resolved hydrocarbon compounds (U/R; Simoneit, 1984).
$\mathrm{U} / \mathrm{R}$ values were in the range of $0.29-10.44$ with a median of 2.08 , confirming the presence of a petroleum component.

The concentration profiles reflect the relative contribution of different sources. The distribution pattern
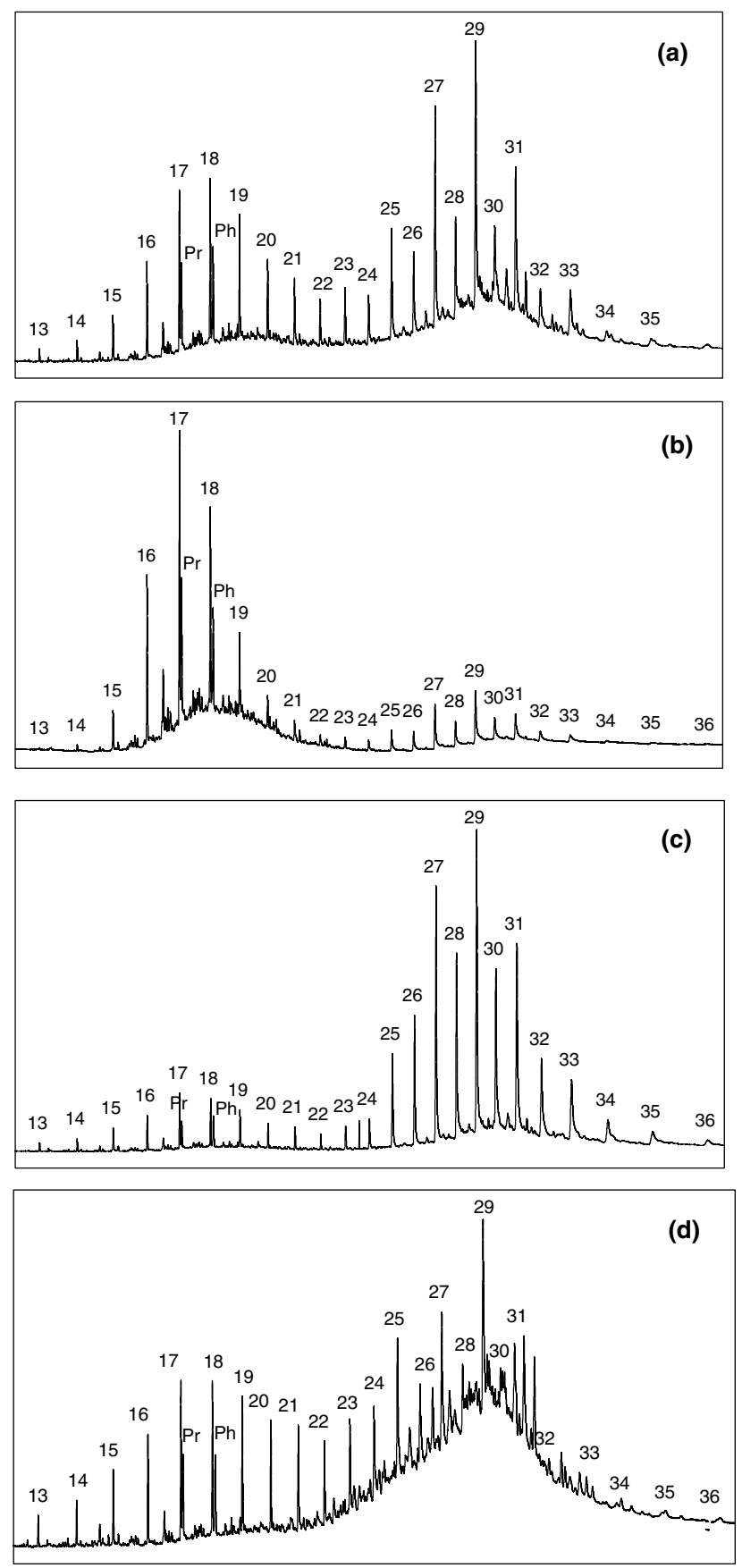

Fig. 4. Representative gas chromatographic patterns of alkane fraction. Numbers in the figure refer to the chain length of $n$-alkanes. $\mathrm{Pr}$, pristane; $\mathrm{Ph}$, phytane. 
from aliphatic hydrocarbons in our study can be basically divided into four types, and representative GC profiles are presented in Fig. 4:

Type A, with a bimodal $\mathrm{C}_{\max }$ pattern for the UCM, a minor maximum at about $\mathrm{C}_{17}$ and a major one at $\mathrm{C}_{27}$, together with a predominance of odd/even carbon numbers in the high molecular homologues, is the most prevalent. The UCM is considered to have an anthropogenic source, while the higher molecular weight $n$-alkanes with a strong preference of odd to even carbon numbers result from the epicuticular waxes of higher plants (e.g. Schneider et al., 1983); this means that the aliphatic hydrocarbons in soils from the Beijing area are from mixed sources, i.e., petroleum and higher plant waxes.

Type B, with the UCM peak with a maximum at $\mathrm{C}_{16}$ $\mathrm{C}_{20}$ and a minor odd/even predominance, was probably caused by both a microbial hydrocarbon contribution and a slight higher plant wax contribution. A small "hump" and preference for odd/even carbon numbers found in type $\mathrm{C}$ gas chromatograms indicated the least fossil fuel input. A significant UCM with maximum at $\mathrm{C}_{27}-\mathrm{C}_{33}$ was observed in the type $\mathrm{D}$ distribution, which is characteristic of strong anthropogenic impact.

The CPI has been a useful parameter for estimating biogenic or anthropogenic contributions since it was first put forward (Bray and Evans, 1961). The $n$-alkanes from epicuticular waxes of higher plants show a pronounced odd carbon number predominance, while fossil fuel and microbial hydrocarbons exhibit CPI $\sim 1$. The carbon number ranges used for calculations are different among different researchers (Kavouras et al., 2001; Colombo et al., 1989; Simoneit and Mazurek, 1982). In the present study, the CPI for $n$-alkanes was calculated as follows: $\mathrm{CPI}_{1}$ (whole range for $n$-alkanes) $=\sum\left(\mathrm{C}_{13}\right.$ $\left.\mathrm{C}_{35}\right) / \sum\left(\mathrm{C}_{14}-\mathrm{C}_{36}\right) ; \quad \mathrm{CPI}_{2} \quad$ (petrogenic $n$-alkanes $)=$
$\sum\left(\mathrm{C}_{13}-\mathrm{C}_{23}\right) / \sum\left(\mathrm{C}_{14}-\mathrm{C}_{24}\right)$; $\mathrm{CPI}_{3}$ (higher plant wax $n$-alkanes $)=\sum\left(\mathrm{C}_{25}-\mathrm{C}_{35}\right) / \sum\left(\mathrm{C}_{26}-\mathrm{C}_{36}\right)$. $\mathrm{CPI}_{1}$ values were in the range of $0.86-4.26$ with a median value of 1.64 , comparable to the aerosol values for Beijing (Li et al., 2001), indicating a similar origin. The contour map of $\mathrm{CPI}_{1}$ is presented in Fig. 5. It was found that the highest $\mathrm{CPI}_{1}$ value was located at the southwest site of the city, indicating a higher relative proportion of vascular plant $n$ alkanes in these samples and the lowest anthropogenic source input because the sampling areas were on agricultural land. In addition, $\mathrm{CPI}_{2}$ values ranged from 0.38 to

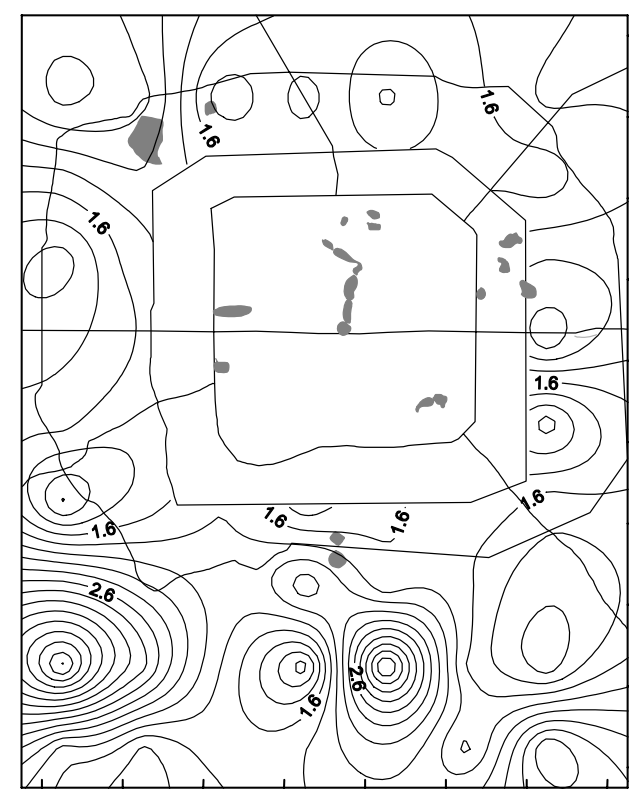

Fig. 5. The contour map of $\mathrm{CPI}_{1}$ in soil samples from the Beijing outskirts.


Fig. 6. Four types of $\mathrm{WaxC}_{n}$ vs. carbon number plots. 
1.39 with a median of 1.05 , typical of a petroleum origin. $\mathrm{CPI}_{3}$ values varied between 0.59 and 21.84 with a median of 2.69, suggesting leaf epicuticular waxes as the predominant source for this $n$-alkane range in most samples.

The $\mathrm{MH}$ index in most samples was at $\mathrm{C}_{29}, \mathrm{C}_{31}$, and $\mathrm{C}_{27}$, indicating that vascular plants sources played a very important role. A lower molecular weight $\mathrm{C}_{\max }$ around $\mathrm{C}_{17}$ and $\mathrm{C}_{21}$ was also observed in several samples. Studies of aerosols in the Beijing area found that $\mathrm{MH}$ indices in most winter and spring samples were at $\mathrm{C}_{29}, \mathrm{C}_{31}$, while in summer and autumn, lower molecular weight $\mathrm{C}_{\max }$ around $\mathrm{C}_{23}$ and $\mathrm{C}_{25}$ were observed (Li et al., 2001).
The ratios of the sum of all $n$-alkanes to $C_{16}$ were also estimated and were from 10.34 to 147.64 with a median of 27.72. High and low values can be interpreted to be derived from biogenic and oily sources, respectively (Colombo et al., 1989)

Fossil fuel characteristics are $\mathrm{CPI}>1, \mathrm{~L} / \mathrm{H}>1$, U/R $>1$ and presence of fossil hopanoids, while characteristic diagnostic indices for urban dust and vegetation fires are $\mathrm{CPI} \sim 1.5$ and $\mathrm{L} / \mathrm{H}<1$, but urban dust shows a relatively higher U/R value, about 4.5 (Fernandes and Brook, 2003). Minor homologues $<n-\mathrm{C}_{20}$ may have an origin from microbial detritus (Simoneit et al., 1991). In the soil samples studied, the ratio of $\mathrm{L} / \mathrm{H}$ was quite varied, suggesting complicated sources.

(a) $30 \alpha$
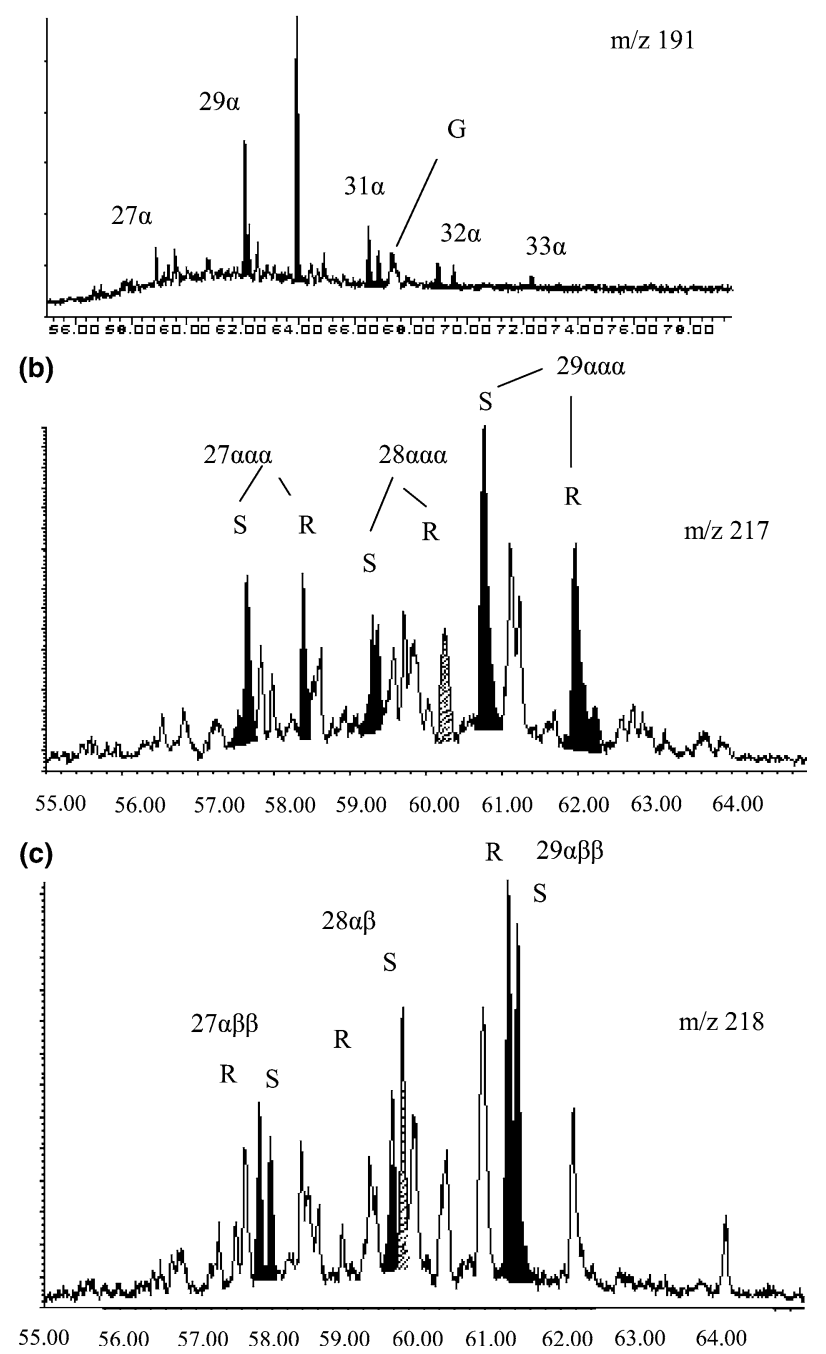

Fig. 7. Examples of mass framentograms: (a) $m / z 191$ for triterpanes, solid peaks are the $17 \alpha(\mathrm{H}), 21 \beta$ (H)-hopane series, $\mathrm{G}$ stands for gammacerane; (b) $m / z 217$ and (c) $m / z 218$ key ion for steranes, solid peaks: $\alpha \alpha \alpha=5 \alpha(\mathrm{H}), 14 \alpha(\mathrm{H}), 17 \alpha(\mathrm{H})$-steranes, $\alpha \beta \beta=5 \alpha(\mathrm{H}), 14 \beta$ $(\mathrm{H}), 17 \beta(\mathrm{H})$-steranes, $\mathrm{R}$ and $\mathrm{S}=\mathrm{C}-20 \mathrm{R}$ and $\mathrm{S}$ configuration. 
Another important parameter to reconcile sources is $\mathrm{WaxC}_{n}$. This is calculated as follows: $\mathrm{WaxC}_{n}=\mathrm{C}_{n}-0.5$ $\left(\mathrm{C}_{n+1}+\mathrm{C}_{n-1}\right)$ and negative values are taken as zero (Kavouras et al., 1999). The relative concentrations of $\mathrm{WaxC}_{n}$ vs. carbon number were plotted. These plots show a quite different $n$-alkane distribution pattern. Figure 6 shows four main types. Type A was the most frequently observed, followed by type $\mathrm{D}$. The percentage of concentration of biogenic wax $n$-alkanes to the total $n$-alkane concentration ranged from $10.52 \%$ to $59.02 \%$, with a median value of $26.58 \%$. The wax composition signature was large, compared with data for aerosols from Santiago de Chile (4.55-20.83\%; Kavouras et al., 1999) and Guangzhou (5.2-19.4\%; Bi et al., 2002), suggesting a higher relative proportion of vascular plant waxes in the Beijing soil samples.

\subsection{Molecular markers}

The presence of $\mathrm{Pr}$ and $\mathrm{Ph}$, indicative of petrochemical use (Simoneit, 1984), was observed in all samples. The levels of $\mathrm{Pr}$ and $\mathrm{Ph}$ were both in the range of $0.02-0.87 \mu \mathrm{g} / \mathrm{g} . \mathrm{C}_{17} / \mathrm{Pr}$ and $\mathrm{C}_{18} / \mathrm{Ph}$ were used to indicate microbial degradation. Biodegradation rates for $n$-alkanes are faster than those of $\mathrm{Pr}$ and $\mathrm{Ph}$ (Chaineau et al., 1995); therefore, the lower indices suggested the presence of degraded oil and the higher values fresh oil input. The median values of $\mathrm{C}_{17} / \mathrm{Pr}$ and $\mathrm{C}_{18} / \mathrm{Ph}$ were 1.62 and 1.47 , respectively. $\mathrm{Pr} / \mathrm{Ph}$ ratios for almost all samples were close to 1, higher than the data for aerosols from Beijing (Simoneit et al., 1991). Sample No. 16-11 had the lowest $\mathrm{C}_{17} / \mathrm{Pr}$ value (0.19) and the highest $\mathrm{Pr} / \mathrm{Ph}$ ratio (7.63) due to low amounts of $\mathrm{C}_{17}$ and $\mathrm{Ph}$, rather than a high amount of $\mathrm{Pr}$.

Examples of the petroleum biomarker distribution patterns are shown in Fig. 7. The $17 \alpha(\mathrm{H}), 21 \beta(\mathrm{H})-$ hopane series, characteristic of a petroleum input, was detected in almost all samples using GC-MS. The series maximizes at $\mathrm{C}_{30}$ and also exists in Beijing aerosols (Simoneit et al., 1991). Gammacerane is also present due to most Chinese crude oils being derived from lacustrine sources (Fu et al., 1990; Jiang et al., 1988; Philp and Fan, 1987). Steranes were detected using the $\mathrm{m} / \mathrm{z}$ 217 and $\mathrm{m} / \mathrm{z} 218$ ion peaks in the GC-MS data. They are common in crude oils from China.

\section{Conclusions}

Aliphatic hydrocarbons in soils from the Beijing area were mainly from anthropogenic and biogenic sources, based on the distribution patterns, compositional indices and molecular markers. The highest total concentrations of aliphatic hydrocarbons were clustered at the north and northeast sites of the city. The anthropogenic com- ponents comprise mainly petroleum residues, confirmed by UCMs, U/R, Pr, Ph and the $17 \alpha(\mathrm{H}), 21 \beta(\mathrm{H})$-hopane series, gammacerane, $5 \alpha(\mathrm{H}), 14 \alpha(\mathrm{H}), 17 \alpha(\mathrm{H})$ and $5 \alpha(\mathrm{H})$, $14 \beta(\mathrm{H}), 17 \beta(\mathrm{H})$-sterane series. Multivariate statistical analysis reduced the data set to two principal components explaining $82.82 \%$ of the total variance.

\section{Acknowledgements}

This project was supported by the Ministry of Science and Technology of China (G1999045707). We acknowledge the Agilent Company for technical support. The authors would like to express thanks to Dr. Wenjian Lao, Dr. Huiming Chen, and Dr. Xuetong Wang for help during the experiments. Our special thanks go to Professor Phil Mayers, Dr. Maowen Li, Professor J.O. Grimalt and an anonymous reviewer for comments.

\section{Associate Editor-Maowen $\mathbf{L i}$}

\section{References}

Aceves, M., Grimalt, J.O., 1993. Seasonally dependent size distributions of aliphatic and polycyclic aromatic hydrocarbons in urban aerosols from densely populated areas. Environmental Science and Technology 27, 2896-2908.

Bi, X., Sheng, G., Peng, P., Zhang, Z., Fu, J., 2002. Extractable organic matter in $\mathrm{PM}_{10}$ from LiWan district of Guangzhou city, PR China. The Science of the Total Environment 300, 213-228.

Bray, E.E., Evans, D.E., 1961. Distribution of $n$-paraffins as a clue to recognition of source beds. Geochimica et Cosmochimica Acta 22, 2-15.

Chaineau, C.H., Morel, J.L., Oudot, J., 1995. Microbial degradation in soil microcosms of fuel oil hydrocarbons from drilling cuttings. Environmental Science and Technology $29,1615-1621$.

Colombo, J.C., Pelletier, E., Brochu, C., Khalil, M., Catoggio, J.A., 1989. Determination of hydrocarbon sources using $n$ alkane and polyaromatic hydrocarbon distribution indices. Case study: Rio de La Plata estuary, Argentina. Environmental Science and Technology 23, 888-894.

Doskey, P.V., Andren, A.W., 1986. Particulate and vaporphase $n$-alkanes in the northern Wisconsin atmosphere. Atmospheric Environment 20, 1735-1744.

Fernandes, M.B., Brook, P., 2003. Characterization of carbonaceous combustion residues: II. Nonpolar organic compounds. Chemosphere 53, 447-458.

Frysinger, G.S., Gaines, R.B., Xu, L., Reddy, C.M., 2003. Resolving the unresolved complex mixture in petroleumcontaminated sediments. Environmental Science and Technology 37, 1653-1662.

Fu, J.M., Sheng, G.M., Xu, J.Y., Eglinton, G., Gowar, A.P., Jia, R.F., Fan, S.F., Peng, P.A., 1990. Application of biological markers in the assessment of paleoenvironments of Chinese non-marine sediments. Organic Geochemistry 16, 769-779. 
Gagosian, R.B., Peltzer, E.T., Zafiriou, O.C., 1981. Atmospheric transport of continentally derived lipids to the tropical north Pacific. Nature 291, 312-314.

Jiang, Z.S., Philp, R.P., Lewis, C.A., 1988. Fractionation of biological markers in crude oils during migration and the effects on correlation and maturation parameters. Organic Geochemistry 13, 561-571.

Kavouras, I.G., Lawrence, J., Koutrakis, P., Stephanou, E.G., Oyola, P., 1999. Measurement of particulate aliphatic and polynuclear aromatic hydrocarbons in Santiago de Chile: source reconciliation and evaluation of sampling artifacts. Atmospheric Environment 33, 4977-4986.

Kavouras, I.G., Koutrakis, P., Tsapakis, M., Lagoudaki, E., Stephanou, E.G., Bear, D.V., Oyola, P., 2001. Source apportionment of urban particulate aliphatic and polynuclear aromatic hydrocarbons (PAHs) using multivariate methods. Environmental Science and Technology 35, 22882294.

Leuenberger, C., Czuczwa, J., Heyerdahl, E., Giger, W., 1988. Aliphatic and polycyclic aromatic hydrocarbons in urban rain, snow and fog. Atmospheric Environment 22, 695-705.

Li, R.Q., Zhang, Z.Q., Shi, J.H., Liu, X.D., Yu, T., 2001. The analysis of organic compounds of atmospheric aerosols in Beijing. Research of Environmental Sciences 14, 21-23 (in Chinese).

Marty, J.C., Saliot, A., 1982. Aerosols in equatorial Atlantic air: $n$-alkanes as a function of particulate size. Nature 298 , 144-147.

Maldonado, C., Bayona, J.M., Bodineau, L., 1999. Sources, distribution, and water column processes of aliphatic and polycyclic aromatic hydrocarbons in the northwestern Black sea water. Environmental Science and Technology 33, 26932702.

Philp, R.P., Fan, Z., 1987. Geochemical investigation of oils and source rocks from Qianjing Depression of Jianhan Basin, a terrigenous saline basin, China. Organic Geochemistry $11,549-562$.

Prahl, F.G., Crecellus, E., Carpenter, R., 1984. Polycyclic aromatic hydrocarbons in Washington coastal sediments: an evaluation of atmospheric and riverine route of introduction. Environmental Science and Technology 18, 687693.

Schneider, J.K., Gagosian, R.B., Cochran, J.K., Trull, T.W., 1983. Particle size distributions of $n$-alkanes and ${ }^{210} \mathrm{~Pb}$ in aerosols off the coast of Peru. Nature 304, 429-432.

Simoneit, B.R.T., Mazurek, M.A., 1982. Organic matter of the troposphere-II. Nature background of biogenic lipid matter in aerosols over the rural western United States. Atmospheric Environment 16, 2139-2159.

Simoneit, B.R.T., 1984. Organic matter of the troposphere-III. Characterization and sources of petroleum and pyrogenic residues in aerosols over the western United States. Atmospheric Environment 18, 51-67.

Simoneit, B.R.T., Sheng, G., Chen, X., Fu, J., Zhang, J., Xu, Y., 1991. Molecular marker study of extractable organic matter in aerosols from urban areas of China. Atmospheric Environment 25A, 2111-2129.

Tolosa, I., Bayona, J.M., Albaiés, J., 1996. Aliphatic and polycyclic aromatic hydrocarbons and sulfur/oxygen derivatives in northwestern Mediterranean sediments: spatial and temporal variability, fluxes, and budgets. Environmental Science and Technology 30, 2495-2503. 